\title{
Analysis of the Coloration Characteristics of Copper Red Glaze Using Raman Microscope
}

\author{
Hye-Jin Eo and Byung-Ha Lee ${ }^{\dagger}$
}

Department of Material Science \& Engineering, Myongji University, Yong In 449-728, Korea

(Received August 26, 2013; Revised October 12, 2013; Accepted October 14, 2013)

\section{Raman Microscope를 이용한 진사 유약 발색 특성 분석

\author{
어혜진 $\cdot$ 이병하 $^{\dagger}$ \\ 명지대학교 신소재공학과 \\ (2013년 8월 26일 접수 ; 2013년 10월 12일 수정 ; 2013년 10월 14일 채택)
}

\begin{abstract}
This study investigatesthe coloration mechanism by identifying the factor that affects thered coloration of copper red glazesin traditional Korean ceramics. The characteristics of the reduction-fired copper red glaze's sections are analyzed using an optical microscope, Raman spectroscopy, scanning electron microscopy (SEM) and energy dispersive x-ray spectroscopy (EDX). The sections observed using an optical microscope are divided into domains of surface, red-bubble, and red band. According to the Raman micro spectroscopy analysis results, the major characteristic peak is identified as silicate in all three domains, and the intensity of $\mathrm{Cu}_{2} \mathrm{O}$ increases toward the red band. In addition, it is confirmed that the most abundant $\mathrm{CuO}$ exists in the glaze bubbles. Moreover, $\mathrm{CuO}$ and $\mathrm{Cu}_{2} \mathrm{O}$ exist as fine particles in a dispersed state in the surface domain. Thus, $\mathrm{Cu}$ combined with oxygen is distributed evenly throughout the copper red glaze, and $\mathrm{Cu}_{2} \mathrm{O}$ is more concentrated toward the interface between body and glaze. It is also confirmed that $\mathrm{CuO}$ is concentrated around the bubbles. Therefore, it is concluded that the red coloration of the copper red glaze is revealed not only through metallic $\mathrm{Cu}$ but also through $\mathrm{Cu}_{2} \mathrm{O}$ and $\mathrm{CuO}$.
\end{abstract}

Key words: Copper - red, Glass, $\mathrm{Cu}_{2} \mathrm{O}$, Colloid, Raman

\section{1. 서 론}

도자기의 색상은 주로 동 $(\mathrm{Cu})$, 철 $(\mathrm{Fe})$, 코발트 $(\mathrm{Co})$ 의 세 가지의 채색원료를 발색제로 사용하고 있다. 그 외에는 망간 $(\mathrm{Mn})$, 크롬 $(\mathrm{Cr})$, 바나듐 $(\mathrm{V})$ 등 금속을 사용하여 나타 내고 있지만 많이 쓰이지 않는다. 특히 동 $(\mathrm{Cu})$ 은 여러 가 지 색상을 내기 위하여 유약의 조성, 소성할 때 화염의 성질에 의해 다양하게 변화한다. 동은 산화염에서 나오는 색보다 환원염에서 나오는 색이 각양각색의 적색 계열로 발색을 한다. ${ }^{1)}$ 도자기에서는 동의 환원소성에 의한 붉은 색 유약을 가리켜 진사라고 명칭 한다. 본래 진사는 천연 산 광물인 황화수은 $(\mathrm{HgS})$ 의 적색을 진사라고 한다. ${ }^{1}$ 하지 만 진사유약의 성분과는 아무런 관계가 없으며, 일제강점 기에 일본인이 진사처럼 색깔이 붉다는 뜻에서 사용된 언 어로써 단지 그 색이 흡사하기 때문에 붙여진 이름이다. 진사 유약은 동을 사용하여 적색으로 발색시키는 것으로

${ }^{\dagger}$ Corresponding author : Byung-Ha Lee

E-mail : djenahr@naver.com

Tel : +82-31-330-6461 Fax : +82-31-330-6457
매우 어려운 제작 기법 중 하나이다. 도자기 가운데 가장 요변이 심하여 만들기도 어렵지만 원하는 색조가 일정하 게 나오지 않는 유약으로 널리 알려져 있다.,3) 그 동안 진사유약에 대한 많은 연구가 이루어졌으나 아직까지 모 든 진사 발색의 정확한 사용재료나 성분의 정확한 조성 비를 알 수 있는 연구결과는 부족한 편이다. 또한 진사유 약은 유약안의 산화 제 1 구리 $(\mathrm{CuO})$ 가 고온의 환원소성 에 의해서 이루어지기 때문에 구리의 휘발이 많이 일어 나고, ${ }^{1)}$ 구리의 결정 성장에 의해 발색이 이루어져 ${ }^{45}$ 발색 조건이 매우 까다롭다. 그래서 진사 유약의 발색기구도 지금까지 명확히 밝혀지지 않았다.

본 연구에서는 진사 유약의 붉은 발색 생성에 영향을 주는 요인을 Raman Micrscope를 사용하여 밝히고, 선행 연구에 대한 명확한 근거를 제시하여 진사유약의 붉은 발 색 기구를 규명하였다.

\section{2. 실험방법}

\section{1. 유약 조합}

유약 재료는 국내에서 생산되는 부여 장석, 청주 석회 
Table 1. Chemical Compositions of Raw Materials

\begin{tabular}{ccccccccc}
\hline & $\mathrm{SiO}_{2}$ & $\mathrm{Al}_{2} \mathrm{O}_{3}$ & $\mathrm{Fe}_{2} \mathrm{O}_{3}$ & $\mathrm{MgO}$ & $\mathrm{CaO}$ & $\mathrm{Na}_{2} \mathrm{O}$ & $\mathrm{K}_{2} \mathrm{O}$ & $\mathrm{Ig} \cdot \operatorname{loss}$ \\
\hline Albite (Buyeo) & 75.89 & 14.86 & 0.08 & - & 0.45 & 4.75 & 3.82 & 0.15 \\
Limestone (Chungju) & 4.00 & 1.12 & 0.20 & 2.20 & 91.97 & - & 0.18 & 0.33 \\
Kaolin (Hadong) & 53.90 & 38.22 & 0.59 & 0.22 & 5.11 & 1.14 & 0.61 & 1.79 \\
Quartz (Buyeo) & 99.69 & 0.15 & 0.02 & - & 0.04 & - & 0.01 & 0.09 \\
\hline
\end{tabular}

Table 2. Seger Formula of Copper - Red Glaze

\begin{tabular}{|c|c|c|c|c|c|}
\hline 0.2130 & $\mathrm{KNaO}$ & & & & \\
\hline 0.4506 & $\mathrm{CaO}$ & 0.2966 & $\mathrm{Al}_{2} \mathrm{O}_{3}$ & 2.7696 & $\mathrm{SiO}_{2}$ \\
\hline 0.0267 & $\mathrm{MgO}$ & & & & \\
\hline 0.3096 & $\mathrm{BaO}$ & & $\mathrm{CuO} 0.5$ & $\mathrm{wt} \%$, B & \\
\hline
\end{tabular}

석, $\mathrm{BaCO}_{3}$, 하동 카올린, 부여규석을 사용하였으며 이들 원료의 성분 분석은 Table 1에 나타내었다. 이들 원료는 ball mill로 분쇄하여 $325 \mathrm{mesh}$ 체를 전통시켜 사용하였다. 또한 $\mathrm{BaCO}_{3}$ (Duksan, chemical pure), 발색제로는 Copper(II) Oxide (Duksan, chemical pure)를 사용하였으며, 발색보조제 로 Tin(IV) Oxide (Junsei, chemical pure)와 Bone Ash를 첨가하였다.

안정된 붉은 발색을 나타내는 진사유약의 조합은 Table 2 에 Seger formula로 나타낸 식에 따라 유약의 원료를 정 량한 후 적정량의 물을 첨가하여 magnetic stirrer로 균질 혼합하여 백자 시험편에 약 $1.5 \mathrm{~mm}$ 의 두께가 되도록 시 유하였다.

소성은 $0.1 \mathrm{~m}^{3}$ 가스가마를 사용하여 Fig. 1에서 나타낸 schedule에 따라 $900^{\circ} \mathrm{C}$ 까지 산화소성하고 그 후 환원분위 기로 $1240^{\circ} \mathrm{C}$ 까지 승온 한 뒤 최고온도에서 60 분 soaking 시킨 후 로를 밀폐시키고 자연 냉각하였다.

\section{2. 특성분석}

소성된 시험편은 diamond cutter로 잘라낸 후 단면을 광 학현미경을 이용하여 100 배 확대 촬영하여 발색된 형태 를 관찰하였다. 유약 내에 존재하는 구리의 화학적 상 태를 확인하기 위하여 유약의 부분 시험편을 Raman microscope (Dimention D2, Lambda Solution, Inc, U.S.A) 분석을 하였다. 또한 미세조직을 관찰하기위하여 $\mathrm{SEM}$ (Scanning Electron Micro Scopy, SS-550, Shimadzu)과 원소 의 분포상태를 알아보기 위하여 $\operatorname{EDX(Energy~Dispersive~}$ X-ray spectroscopy) 분석을 행하였다.

\section{3. 결과 및 고찰}

\section{1. 유약 단면의 광학 현미경 관찰}

진사유약의 발색된 형태를 관찰하고 유약 층에 대한 분 석을 위하여 유약 단면을 현미경으로 관찰한 결과를 Fig. 2 에 나타내었다. 광학 현미경을 이용하여 100 배로 확대하

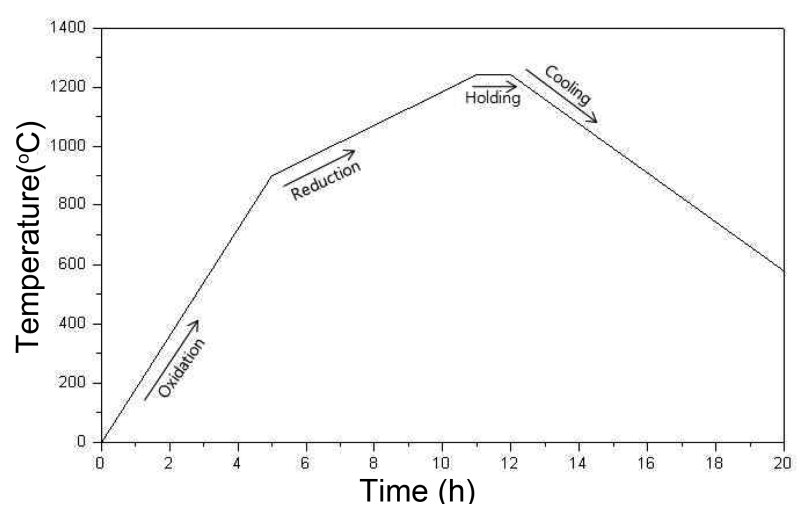

Fig. 1. Basic firing schedule.

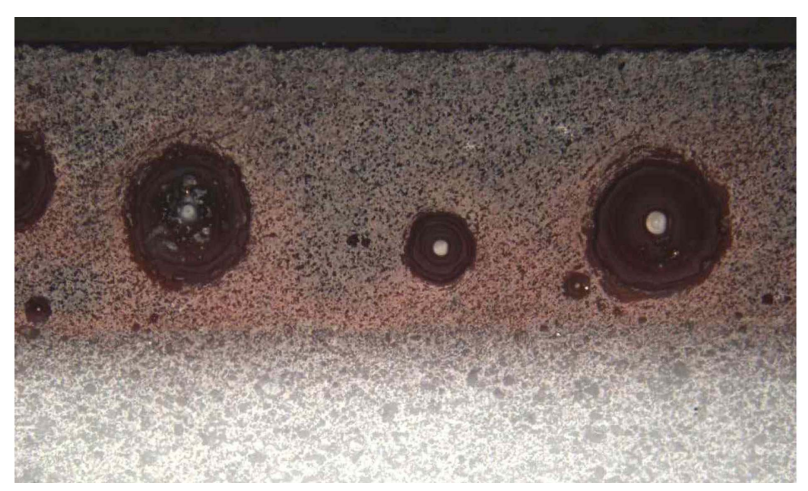

Fig. 2. Optical microscopy image of glazes.

여 유약 층 내의 기공의 분포도와 형태, 유약층의 두께 등에 대한 정보를 확인하였다. 그 결과 전체 유약 층은 $47.31 \mu \mathrm{m}$ 의 두께를 가지며 붉은 색상은 유약의 표면보다 중간층에 넓게 나타났다. 적색 층의 폭은 대략 $29.68 \mu \mathrm{m}$ 정도로 고르게 분포하였다. 또한 유약 내부에는 기포가 형성이 되어있다는 것이 흥미로웠다. 이때 기포는 소성 중에 이미 유약의 표면이 먼저 유리화되어 소지와의 경 계층에 있던 기포가 빠져나오지 못한 것으로 보이며 기 포 주변에 붉은 색상이 집중되어 나타났다. 주로 크기가 

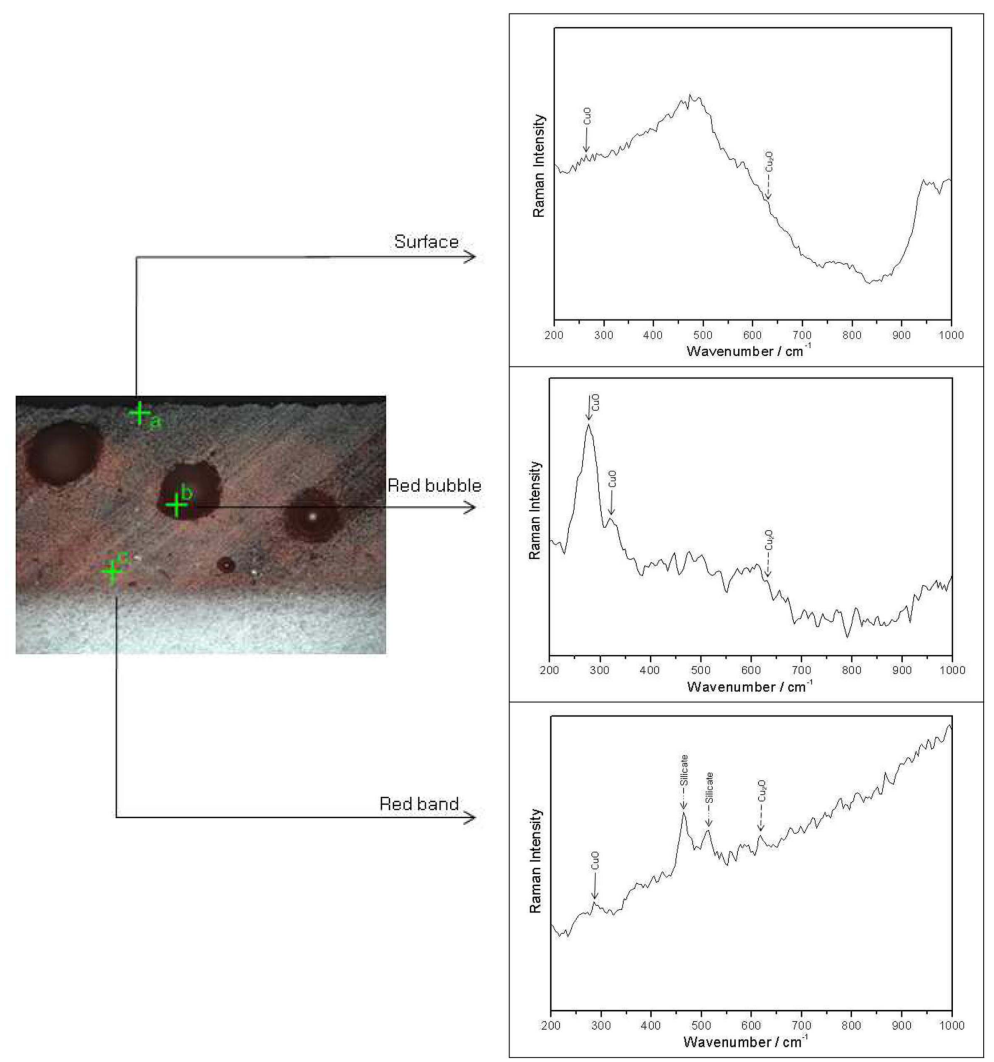

Fig. 3. Raman microscopy spectra of copper-red glaze.

큰 기포는 유약 층의 중심부에 형성되며, 작은 크기의 기 포는 소지와 유약의 경계에 주로 형성되고 있다. 하지만 유약의 표면에는 기포가 존재하지 않았으며, 유약의 색상 도 붉은 색상이 아닌 무색으로 확인할 수 있다. 기포가 없는 유약의 표면에 색상이 나타나지 않는 이유는 소성 시 일어나는 구리의 휘발로 인하여 구리가 없거나 극히 미량이기 때문에 무색으로 나타나는 것이다. ${ }^{3-5)}$

\section{2. 유약 발색 특성 분석}

진사유약의 정확한 발색기구를 알아보기 위하여 Raman 분석을 시행하여 산소와 결합된 다른 구리 화합물의 존 재 여부를 확인하여 보았다. Fig. 3은 광학현미경에서 얻 은 정보를 바탕으로 유약 단면을 surface, red-bubble, redband layer로 구분하여 각각 micro Raman spectroscopy 분석을 시행한 결과를 나타내었다. Raman spectrum에서 $\mathrm{CuO}$ 의 특성 band는 $288 \mathrm{~cm}^{-1}, 330 \mathrm{~cm}^{-1}$ 이며, $\mathrm{Cu}_{2} \mathrm{O}$ 의 특 성 band는 $633 \mathrm{~cm}^{-1}$ 에서 나타난다. Fig. 3 의 결과 surface layer spectrum은 주로 비정질의 silicate 특성 band로 $430 \mathrm{~cm}^{-1}$, $480 \mathrm{~cm}^{-1}, 600 \mathrm{~cm}^{-1}, 795 \mathrm{~cm}^{-1}, 960 \mathrm{~cm}^{-1}, 1070 \mathrm{~cm}^{-1}$ 의 경향성 을 띠는 glass로 존재하고 있었다. 그리고 $293 \mathrm{~cm}^{-1}$ 에서 $\mathrm{CuO}$ 의 특성 band와 $634 \mathrm{~cm}^{-1}$ 에서는 $\mathrm{Cu}_{2} \mathrm{O}$ 의 특성 band가 약한 band로 나타났다. Red-bubble spectrum에서는 281,
$319 \mathrm{~cm}^{-1}$ 에서 $\mathrm{CuO}$ 의 특성 bands ${ }^{1,6,7)}$ 가 강하게 나타나 기 포 주변에는 $\mathrm{CuO}$ 가 집중되어 분포하고 있는 것을 보여 주고 있다. 그리고 $630 \mathrm{~cm}^{-1}$ 에서는 $\mathrm{Cu}_{2} \mathrm{O}$ 의 특성 band가 약하게 존재하고 있었다. Red-band spectrum은 silicate 특 성 band가 주로 나타나지만 $618 \mathrm{~cm}^{-1}$ 에서 $\mathrm{Cu}_{2} \mathrm{O}$ 의 특성 band와 $285,315 \mathrm{~cm}^{-1}$ 에서 $\mathrm{CuO}$ 의 특성 band도 약하지만 함께 존재하고 있었다. Raman 분석을 통하여 진사유약의 표면은 주로 유리질로 덮여있고 유약 내의 기포 부근에 는 $\mathrm{CuO}$ 의 입자가 집중되어 있으며 유약과 소지의 경계 면으로 갈수록 유리질과 $\mathrm{Cu}_{2} \mathrm{O}$ 의 colloid 입자가 집중적으 로 분산되어 존재하고 있다는 것을 알 수 있었다.

Surface layer는 현미경 관찰로는 색상이 나타나지 않았 지만 Raman 분석에서는 $\mathrm{CuO}$ 와 $\mathrm{Cu}_{2} \mathrm{O}$ peak가 미세하게 존재하는 것을 볼 수 있었다. Surface layer에서의 구리의 분포를 자세히 확인하기 위하여 Raman microscopy image mapping을 통하여 분석한 결과를 Fig. 4에 나타내었다. Surface layer에는 수많은 입자들이 비정질로 존재하고 있 어 그 위치마다 다른 Raman band의 경향을 띠고 있었다. Fig. 4 와 같이 3 부분의 Point를 분석한 결과 Point $\mathrm{A}$ 와 B 영역은 silicate의 Raman band였다. 그러나 Point $\mathrm{C}$ 영역 에서는 $\mathrm{CuO}$ 의 특성 band가 나타나 surface layer에 $\mathrm{CuO}$ 가 존재하고 있다는 것을 확실하게 보여주었다. 또한 $\mathrm{BaO}$, 


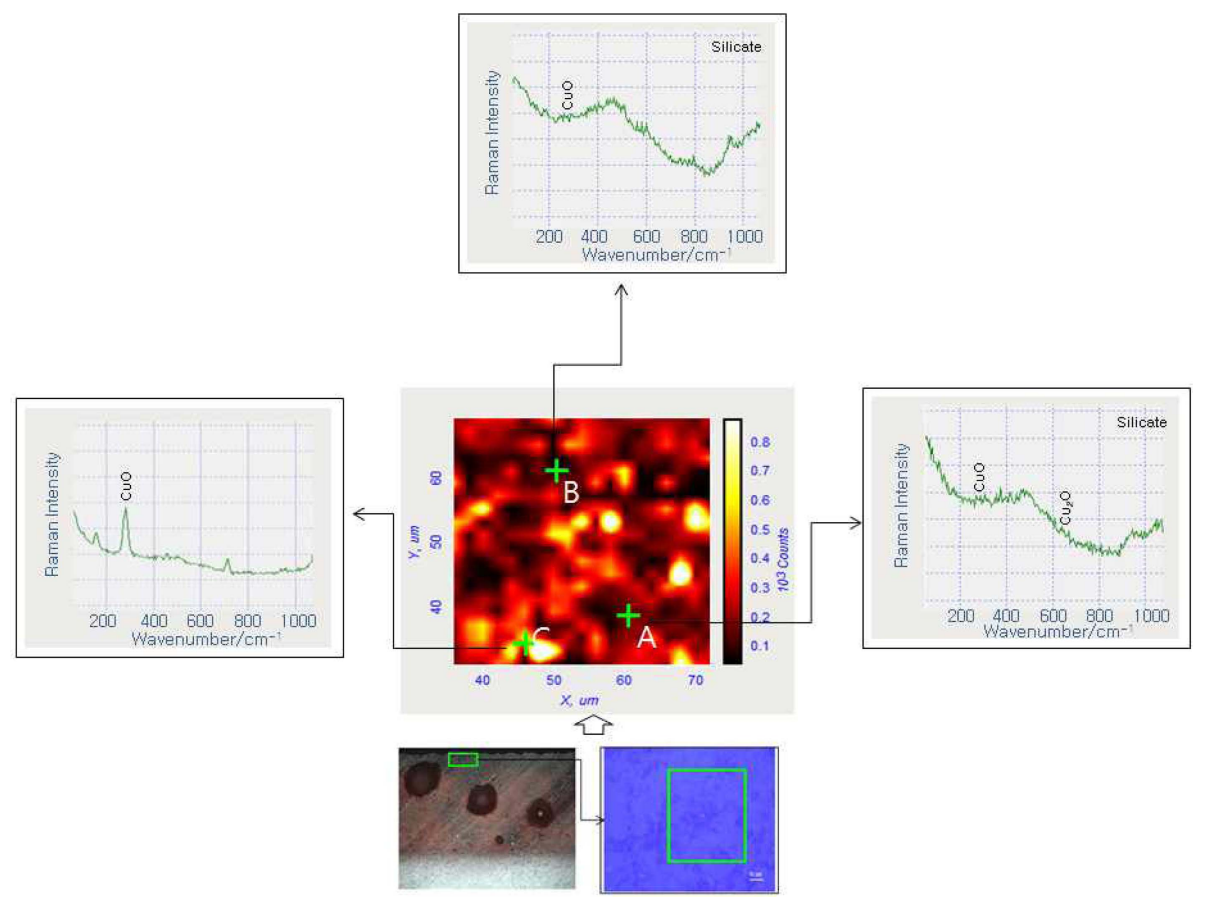

Fig. 4. Image mapping of Raman microscopy analysis of copper-red glaze.
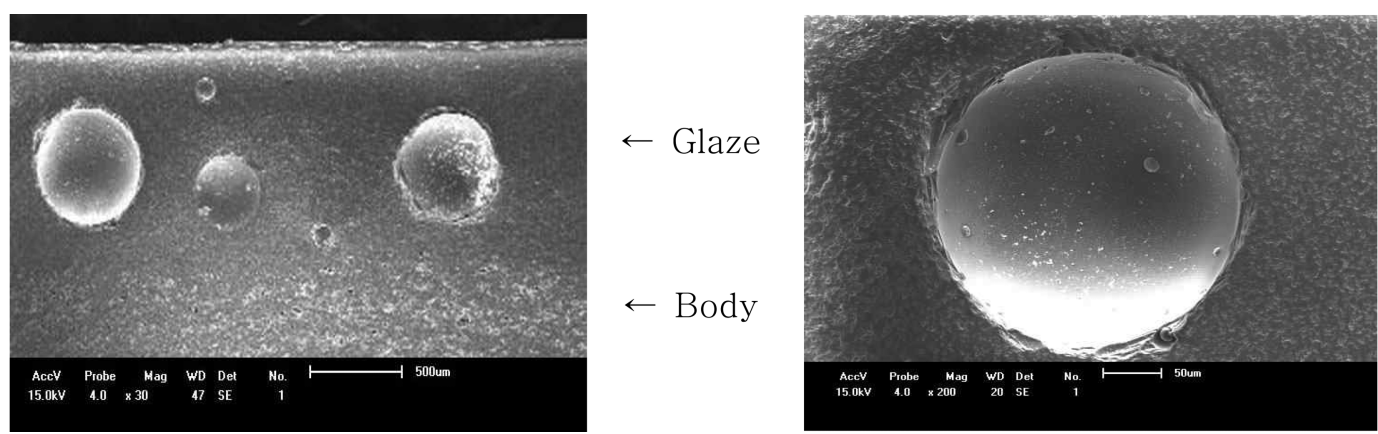

Fig. 5. SEM micrographs of copper-red glaze.

$\mathrm{CaO}$ 의 화합물도 성분이 검출되어 있다. 유약 내에서 존 재하는 $\mathrm{BaO}, \mathrm{CaO}$ 의 성분들은 여러 유약의 재료들이 유 리질로 녹는 것을 도와주면서 구리의 반응성과 발색을 좀 더 좋게 해주는 보조적 역할을 하는 원료로 사용되었기 때문에 surface layer에서 일부 검출된 것으로 보인다. 이 와 같은 결과로 미루어보아 진사유약의 발색은 선행연구 에서 확인하였던 금속성 $\mathrm{Cu}$ 와 유약내부의 영역에 존재하 는 $\mathrm{CuO}, \mathrm{Cu}_{2} \mathrm{O}$ 가 미립자인 colloid 상태로 유약의 모든 영 역에 골고루 분산되어있다는 것을 확인하였다.

\section{3. 유약의 미세 성분 분석}

전자현미경(SEM)을 이용하여 높은 배율에서의 유약의 미세조직과 성분을 관찰하였다. $\mathrm{SEM}$ 으로 관찰한 유약 층 과 유약내의 기포를 확대한 사진을 Fig. 5에 나타내었다. 그 결과 전체적으로 매우 깨끗한 유약의 미세구조를 가
진 상태를 확인할 수 있었다. 유약면에 크고 작은 기포들 이 유약면에 고르게 분포하고 있었으며, 기포 내부를 확 대하여 관찰해본 결과 회색의 원형입자들이 전체적으로 분포하고 있었다.

유약에 사용된 많은 원소들이 어떠한 형태로 분산되어 있는지를 확인하기 위하여 $\mathrm{EDX}$ 분석을 통하여 원소의 분포 상태를 알아보았다(Fig. 6). 그 결과 진사유약 주요 성분인 $\mathrm{SiO}_{2}$ 의 높은 농도로 인하여 유리질인 것을 확인 하였고 $\mathrm{Al}_{2} \mathrm{O}_{3}, \mathrm{Na}_{2} \mathrm{O}, \mathrm{CaO}$ 은 다소 낮지만 전체적으로 균 일하게 분포하고 있었다. 그리고 $\mathrm{Cu}$ 는 3영역 모두 미세 한 입자의 높은 농도로 유약 내부에 분산되어있는 것을 관찰하였다. Raman 분석 유약의 layer를 구분할 수 있는 특성 원소는 확인되지 않았다. 그러나 기포내부의 구리원 소의 분포도를 보면 유약의 표면보다 구리가 더 집중되 어있는 것을 확인할 수 있었다. 


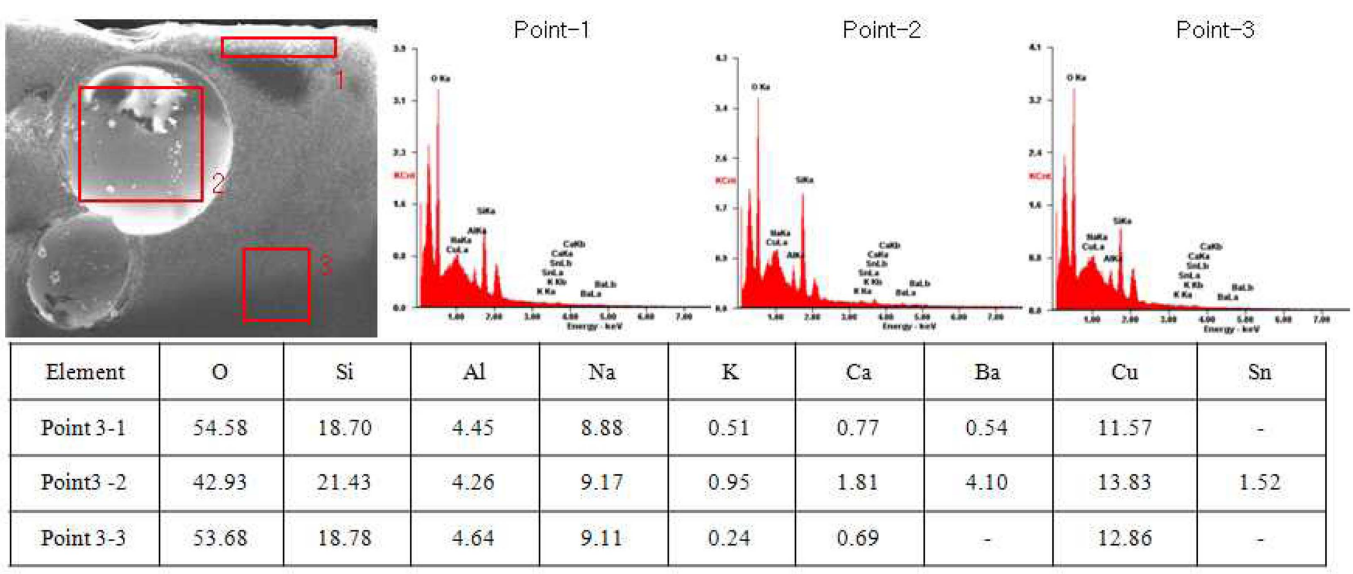

Fig. 6. EDX analysis of copper-red glaze.

\section{4. 결 론}

1. 진사 유약의 단면을 광학현미경으로 관찰한 결과 유 약 내에는 Surface, red bubble, red band 영역으로 구분되 어있었다.

2. 현미경으로 구분된 영역에 존재하는 구리의 화학적 결합 상태를 각각 Raman 분석한 결과 surface는 silicate가 밀집되어 있으며, red bubble 영역은 $\mathrm{CuO}$, red band 영역 은 $\mathrm{Cu}_{2} \mathrm{O}$ 가 집중되어 분포하고 있는 것을 확인 할 수 있 었다.

3. 진사 유약의 주요한 발색 원소는 $\mathrm{Cu}$ 이며, $\mathrm{Cu}$ 는 metallic $\mathrm{Cu}, \mathrm{CuO}, \mathrm{Cu}_{2} \mathrm{O}$ 의 형태로 유약 층의 내부에 분산되어 존 재한다.

4. 유약 내의 구리 입자는 전체적으로 분포하고 있으며 이때 구리 입자는 적색을 갖는 주요한 발색요인으로 작 용하였다.

\section{REFERENCES}

1. H. J. Eo and B. H. Lee, "Coloration Characteristics of Copper Red Glaze,” Kor. J. Mater. Res., 23 [7] 399-403 (2013).

2. J. Zhang. J. Liu, Q. Peng, X. Wang, and T. Li, "Nearly Monodisperse $\mathrm{Cu}_{2} \mathrm{O}$ and $\mathrm{CuO}$ Nanospheres: Preparation and Applications for Sensitive Gas Sensors," Chem. Mater., 18 867-71 (2006).

3. M. S. Yeh, Y. S. Yang, Y. P. Lee, H. F. Lee, Y. H. Yeh, and C. S. Yeh, "Formation and Characteristics of $\mathrm{Cu}$ Colloids from $\mathrm{CuO}$ Powder by Laser Irradiation in 2-propanol," $J$. Phys. Chem. B., 1036851 (1999).

4. M. Wakamatsu and S. Ishida, "Effect of Heating and Cooling Atmospheres on Colors of Glaze and Glass Containing Copper," J. Non-Cryst. Solids, $80412-21$ (1986).

5. M. Wakamatsu, N. Takeuchi, and H. Nagai, "Chemical States of Copper and Tin in Copper Glazes Fired under various Atmospheres," J. Am. Ceram. Soc., 72 [1] 16-19 (1989).

6. S. F. Brown and F. H. Norton, "Constitution of Copper-red Glazes," J. Am. Ceram. Soc., 42 [11] $499-503$ (1959).

7. H. Dai, C. K. Thai, M. Sarikaya, and D. T. Schwartz, "Through-Mask Anodic Patterning of Copper Surfaces and Film Stability in Biological Media," Langmuir, 20 3483-86 (2004). 